\title{
TEXTURE IN Bi-Sr-Ca-Cu-O FILMS PREPARED BY A PAINT-ON METHOD
}

\author{
J.A. SZPUNAR*, P. GANGLI*, S.H. QIU**, I. SHIH**, \\ E. BATALLA*** and E.G. ZWARTZ*** \\ *Department of Metallurgical Engineering, McGill University \\ 3450 University Street, Montreal, Canada, H3A 2 A7. \\ **Department of Electrical Engineering, McGill University \\ 3450 University Street, Montreal, Canada, H3A 2 A7. \\ ***Department of Physics, Royal Military College of Canada, \\ Kingston, Canada, K7L 4Z4
}

\begin{abstract}
The texture and structure of polycrystalline films of $\mathrm{Bi}-\mathrm{Sr}-\mathrm{Ca}-\mathrm{Cu}-\mathrm{O}$ prepared by the paint-on method on alumina substrate has been investigated. A large variety of texture strength has been obtained as a result of various processing of $2: 2: 1: 2,1: 1: 1: 2,1: 1: 2: 2$ and $2: 2: 2: 3$ compounds. The X-ray diffraction analysis and measurements of conductivity have shown the presence of a low $\mathrm{T}_{c}$ phase. Imaging of the magnetic field distribution using the Faraday effect and the critical current measurements demonstrated that the critical current is very low. SEM observation of the microstructure indicate that the possible reason of low critical current density is a weak link between high $\mathrm{T}_{c}$ grains.
\end{abstract}

\section{INTRODUCTION}

High $\mathrm{T}_{\mathrm{c}}$ superconductors, in general, show transport critical current densities $\left(J_{c}\right)$ that are too low for various practical applications. It has been widely recognized 1,2 that texture plays an important role in increasing the critical current. For this reason there has been a considerable research effort made to introduce a strong texture in high $\mathrm{T}_{\mathrm{c}}$ ceramics. Bulk $\mathrm{Y}-\mathrm{Ba}$ $\mathrm{Cu}-\mathrm{O}$ superconductors have been already textured by a number of different techniques ${ }^{3}$, but the highest $J_{c}$ values resulted from a directional solidification technique termed as "melt textured growth". Using this technique the values of $17000 \mathrm{~A} / \mathrm{cm}^{2}$ at zero field and $4000 \mathrm{~A} / \mathrm{cm}^{2}$ at $\mathrm{H}=1 \mathrm{~T}$ field were reported4.

It has also been demonstrated 4 , that the ratio of the critical current density at the grain boudaries to that of the average value can change by two 
orders of magnitude. Texturing plays an important role, since it not only aligns the superconductive $\mathrm{Cu}-\mathrm{O}$ planes parallel to one plane but in addition introduces selective grain boundaries where the crystals are misoriented relative to their neighbors by a rotation about the c-axis. The existence of such boundaries reduces the weak link between the high $\mathrm{T}_{\mathrm{c}}$ grains.

\section{EXPERIMENTAL}

Specimens of $\mathrm{Bi}-\mathrm{Sr}-\mathrm{Ca}-\mathrm{Cu}-\mathrm{O}$ ceramics were prepared, using a painton method. The starting materials were powders of $\mathrm{Bi}_{2} \mathrm{O}_{3}, \mathrm{SrCO}_{3}, \mathrm{CaCO}_{3}$ and $\mathrm{CuO}$ with atomic ratios of $\mathrm{Bi}: \mathrm{Sr}: \mathrm{Ca}: \mathrm{Cu}$ given in Table 1 . The powders were mixed with triethanolamine and then the mixture was painted on to alumina substrates.

Table 1 Fabrication Conditions of the samples

\begin{tabular}{|c|c|c|c|c|}
\hline \multirow{2}{*}{$\begin{array}{c}\text { Sample } \\
\text { No. }\end{array}$} & \multirow{2}{*}{ Bi:Sr:Cu:Ca } & \multicolumn{3}{|c|}{ Heat Treatment Cooling } \\
\cline { 3 - 5 } & & $\mathrm{T}\left({ }^{\circ} \mathrm{C}\right)$ & $\mathrm{t}(\mathrm{min})$. & \\
\hline P022 & $2: 2: 1: 2$ & 400 & 30 & $0.5^{\circ} \mathrm{C} / \mathrm{min}$. \\
& & 900 & 20 & $400^{\circ} \mathrm{C}$, off \\
\hline P023 & $2: 2: 1: 2$ & 890 & 10 & $2^{\circ} \mathrm{C} / \mathrm{min}$. \\
& & 880 & 60 & $580^{\circ} \mathrm{C}$, off \\
\hline P024 & $1: 1: 1: 2$ & 400 & 5 & off \\
& & 860 & 800 & \\
\hline P028 & $1: 1: 1: 2$ & 400 & 30 & $400^{\circ} \mathrm{C}$ \\
& & 900 & 20 & off \\
& & 850 & 50 & \\
\hline P036 & $2: 2: 2: 3$ & 400 & 30 & $400^{\circ} \mathrm{C}$ \\
& & 900 & 20 & off \\
& & 850 & 50 & \\
\hline
\end{tabular}

Following that, the samples were baked in an oven at $180^{\circ} \mathrm{C}$ for 30 minutes. This treatment was necessary to evaporate the triethanolamine, then they were placed at room temperature in a furnace and heated up to $400^{\circ} \mathrm{C}$ in about 15 minutes. They were kept at this temperature for 30 minutes.

In the next step the specimens were subjected to various heat treatments, see Table 1 . In general they were heated up to approximately $900^{\circ} \mathrm{C}$ (it took 25 minutes to heat up the furnace from 400 to $900^{\circ} \mathrm{C}$ ) and at 
this temperature the specimens were held for 20 minutes. Subsequently, the temperature of the furnace was kept constant (for different specimens) between 720 to $875^{\circ} \mathrm{C}$ for $1-3$ hours, and then our specimens were cooled down to about $400^{\circ} \mathrm{C}$ and the furnace was turned off. After 3 hours the specimens were removed from the furnace. Parameters of the heat treatment for all investigated specimens are given in Table 1.

$\mathrm{X}$-ray powder diffraction patterns which were used for structure identification were measured using a Rigaku rotating anode $\mathrm{X}$-ray source, with $\mathrm{Cu} \mathrm{K} \mathrm{K}_{\mathrm{a}}$ radiation. Texture was measured using a Siemens D-500 diffractometer equipped with a texture goniometer. Pole figures were measured using the reflection technique, up to maximum tilt of the specimen of $80^{\circ}$ in $5^{\circ}$ in polar and azimuthal angular intervals. The results were corrected for absorption and defocussing using a standard powdered random specimen. The pole figures were normalized within the available interval of distribution of crystallographic planes and the intensity on the pole figures was shown using multiples of random intensities.

The experimental apparatus which was used to display the magnetic field distribution in the specimens using the Faraday effect was described in the paper by Batalla et al.5.

\section{STRUCTURE AND TEXTURE}

$\mathrm{X}$-ray structure identification of all $\mathrm{Br}-\mathrm{Sr}-\mathrm{Ca}-\mathrm{Cu}-\mathrm{O}$ specimens was made assuming a tetragonal cell with $\mathrm{a}=5.39 \AA$ and $\mathrm{c}=30.6 \AA$. A typical diffraction pattern obtained is given in Fig. 1. One has to stress however, that the strucutre identification does not enable us to distinguish between the so-called high $\mathrm{T}_{c}$ phase $\left(\mathrm{T}_{\mathrm{c}}=105^{\circ} \mathrm{K}\right)$ and low $\mathrm{T}_{\mathrm{c}}$ phase $\left(\mathrm{T}_{\mathrm{c}}=80^{\circ} \mathrm{K}\right)$ and that there are at least three different phases having tetragonal or pseudotetragonal layered structures in the present system.

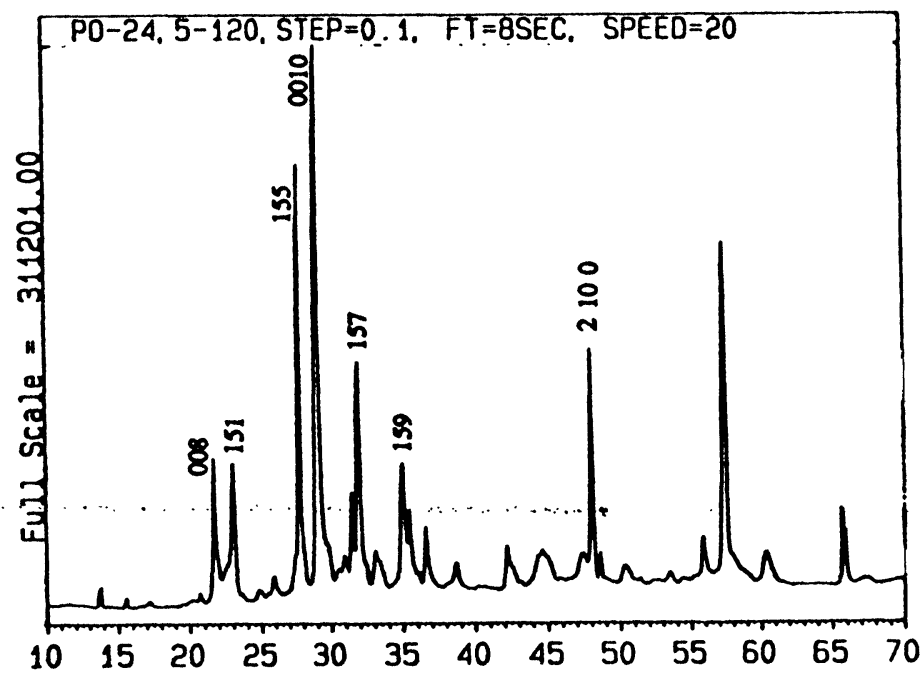

Figure 1: A typical powder diffraction pattern for $\mathrm{Br}-\mathrm{Sr}-\mathrm{Cu}-\mathrm{O}$ specimen obtained using Rigaku rotating anode source, $\mathrm{Cu} \mathrm{Ka}$ radiation. 
The results obtained by Onoda et al. 6 indicate that the material with $\mathrm{T}_{\mathrm{c}}=80^{\circ} \mathrm{K}$ has a modulated structure. The average structure was identified by them as being orthorhombic, but an electron microscopic observation revealed the presence of modulation along the ' $a$ ' or ' $b$ ' axis suggesting that the satellite lines should appear on the X-ray powder pattern. A proper assignment of the powder $\mathrm{X}$-ray diffraction pattern will therefore require an analysis of the unindexed maxima observed in the polycrystalline specimen and the decision as to whether they represent the satellite reflections or are due to impurity phases.

For all specimens the $(0010)$ reflection was measured, while, other reflections in particular $(155)$ and $(008)+(151)$ were also used to obtain additional pole figures. A large variety of texture strength was recorded in all the materials, however, the texture was of the same type, showing that (001) crystallographic planes oriented parallel to the surface of the specimen.

Depending on processing conditions the strength of texture varied between 1.6 to about 70 random units. Exemplary pole figures are given in Figs. 2.

a)

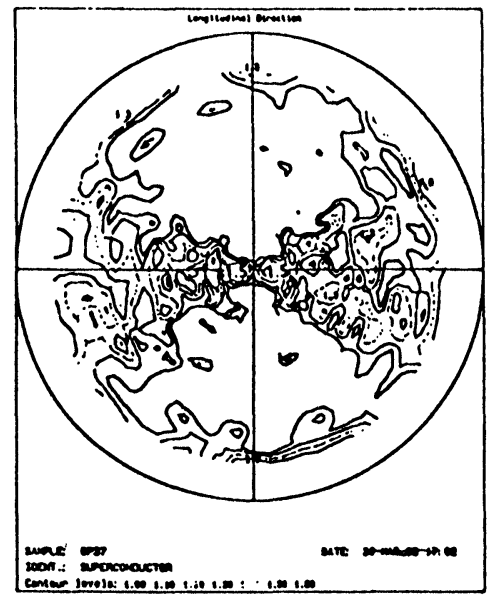

c)

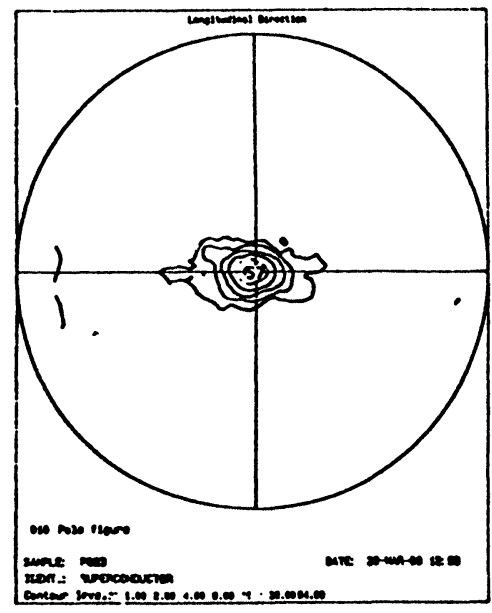

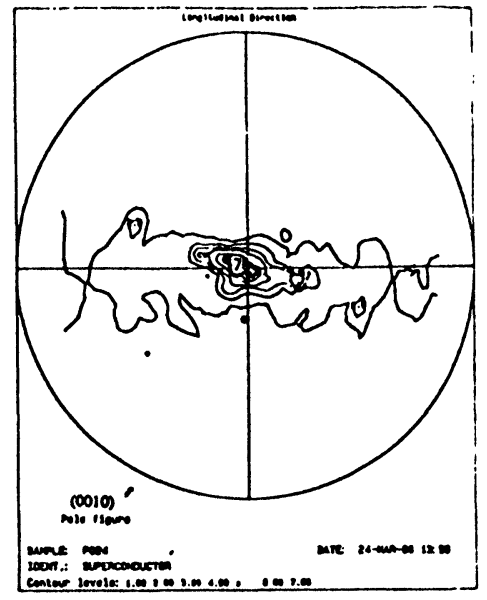

b)

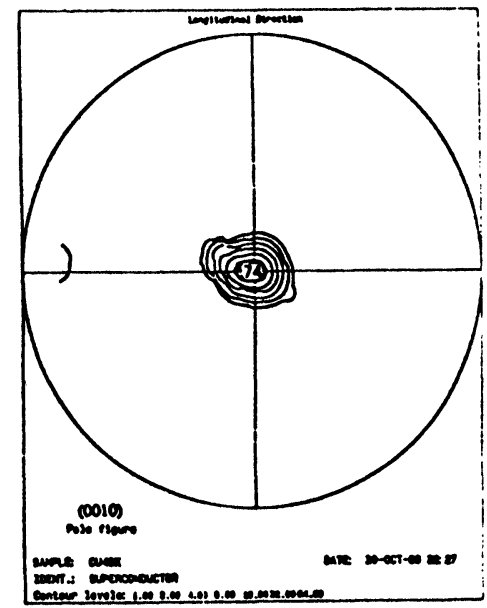

d)

Figure 2: Pole figures measured for $\{0010\}$ Bragg reflection for the following specimens a) $\mathrm{PO} 36$ b) $\mathrm{PO} 24$ c) $\mathrm{PO} 23$ d) $\mathrm{PO} 22$ 
Since the optimal treatment of the specimens is quite complex, we are not yet able at present to suggest an explanation as to what plays a decisive role in formation of a stronger texture.

The resistivity measurement made as functions of temperature (Fig. 3) show the resistivity drag at about $80^{\circ} \mathrm{K}$ which indicate that the high $\mathrm{T}_{c}$ phase $\left(T_{c}=105^{\circ} \mathrm{K}\right)$ may not be present at all and another phase with $T_{c}=$ $80^{\circ} \mathrm{K}$ is dominant.

Microstructural observations using a SEM JEOL microscope revealed needle like phases of two types: large and small needles (Fig. 4). Elemental analysis of various areas of the specimen shows that the composition of a needle phase is bismuth deficient. It is thefore likely, that these small needles represent a non-superconducting phase $\mathrm{Sr}_{14} \mathrm{Cu}_{24} \mathrm{O}_{41}$ which was earlier observed in the bulk Bi-Sr-Ca-Cu-O system.

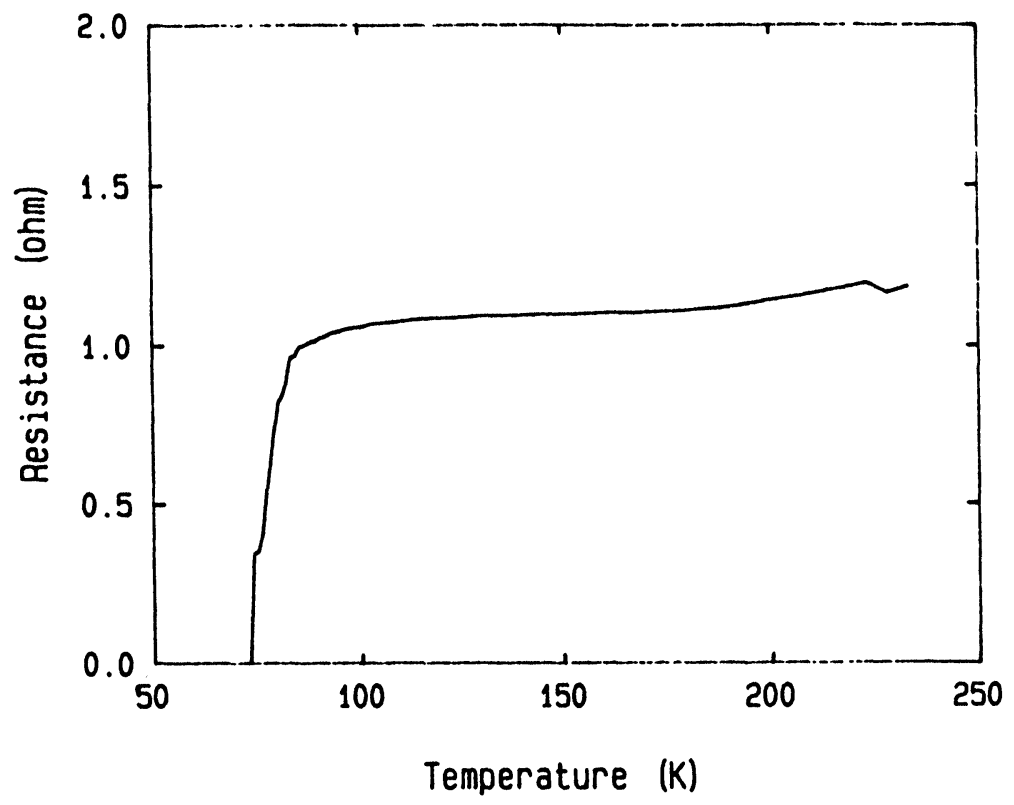

Figure 3: The resitivity measured as a function of temperature. Typical for all specimens.

\section{IMAGING THE MAGNETIC FIELD DISTRIBUTION}

When an external magnetic field is smaller than the lower critical field in any type II superconductors, the field is screened from the interior of the sample by large surface currents. When a field begins to penetrate to the sample the gradient of the magnetic field inside the specimen is related to the critical current by Maxwell's equation. 


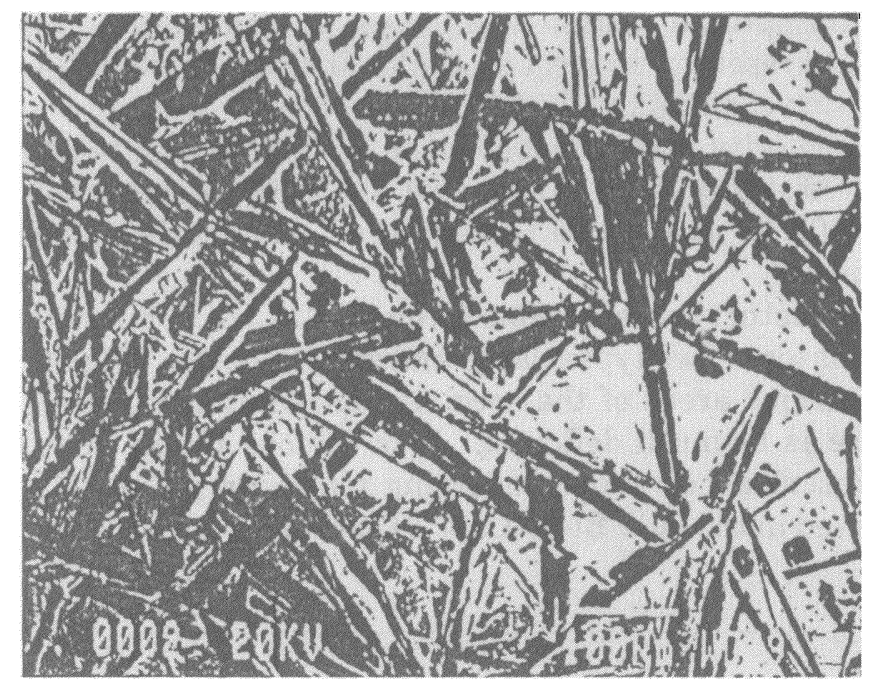

Figure 4: Microstructure of a typical weakly textured specimen. SEM picture taken at $20 \mathrm{kV}$.

Using the magnetooptic method, it is possible to observe the penetration of the magnetic field into the specimen. The method is based on the rotation of the polarization of light in the magnetic field (so called Faraday effect) and was described in detail by Batalla et al.5. This method and equipment was used in our measurements.

The specimen with the strongest texture was analyzed using this magnetooptic method. The sample was cooled in zero magnetic field to $4.2^{\circ} \mathrm{K}$, then the magnetic field was applied and increased to $\sim 1 \mathrm{kGauss}$, then reduced to zero and applied in the reverse polarity. During such cycling a weak optical contrast was observed in the specimen (Fig. 5), demonstrating that the specimen is superconductive, the critical current, however, was very low. The measurements of the critical current density in specimens investigated confirm magnetooptic observations and show that the critical current is lower than $2 \mathrm{~A} / \mathrm{cm}^{2}$.

Our SEM observation of the microstructure seems to show that a possible explanation of such low critical current lies in the weak link regions between the high $\mathrm{J}_{\mathrm{c}}$ grains.

Such links can result from impurity layers along the grain boundaries, or from nonstechiometry near the grain boundaries or in the grains, and from microcracking resulting from anisotropic thermal expansion. A small conductivity may also result from weak links at some high angle boundaries and from the presence of nonsuperconductive phases.

Obviously, the microstructure of our investigated specimens is quite complex. A remarkably strong texturing did not improve the critical current density in the series of specimens we have investigated. 
Figure 5: Optical Faraday's contrast in the P024 specimen at a field of $37 \mathrm{mT}$.

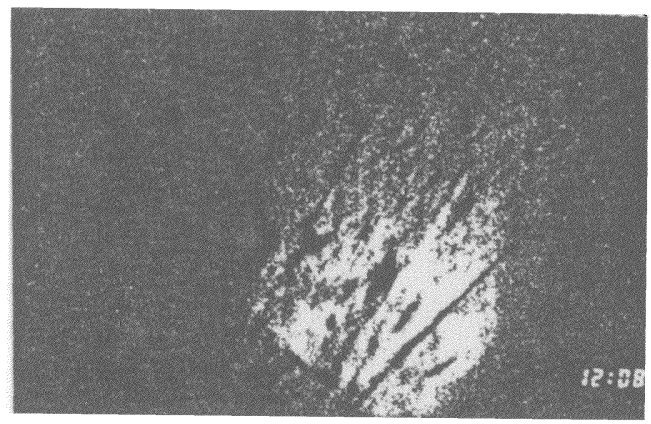

\section{CONCLUSION}

This study has clearly demonstrated that the heat treatment of $\mathrm{Bi}$-Sr$\mathrm{Ca}-\mathrm{Cu}-\mathrm{O}$ films manufactured by a paint-on method affect the texture of the obtained high $T_{c}$ ceramics. Basal crystallographic planes are always parallel to the substrate, but the strength of the texture varies between 1.6 70 units.

Different stechiometric ratios also affect the strength of texturing. Even the strongest texturing did not improve significantly the critical current density. One must add that our strongly textured specimens were better superconductors; and for these specimens a penetration of the magnetic field to the interior of the specimen was observed using a magnetooptical method.

The SEM observation of the microstructure of the specimens revealed a complex multiphase system. Small $\mathrm{J}_{\mathrm{c}}$ capacity most likely is the result of the weak link regions between the high $\mathrm{J}_{\mathrm{c}}$ grains.

The measurements of resistivity versus temperature gives zero resistivity at about $80^{\circ} \mathrm{K}$, which indicates that the high $\mathrm{T}_{\mathrm{c}}$ phase $\left(\mathrm{T}_{\mathrm{c}}=\right.$ $105^{\circ} \mathrm{K}$ ) is not present. The low $T_{c}$ phase is responsible for the existing superconductivity.

\section{REFERENCES}

1. D. Dimos, P. Chaudhari, J. Mannhart and F. Le Loues, Phys. Rev. Lett., 61, (1988), 219.

2. D.B. Knorr and J.D. Livingston, Supercond. Sci. Technol., 1, (1989), 302.

3. P.J. McGinn, W. Chen, Z. Zhu, U. Balachandran and M.T. Lanagan, Physica C, 165 (1990), 480.

4. S. Jin, T. Tiefel, R. Sherwood, R. van Dover, M. Davies, G. Kammelott and R. Fastnacht, Phys. Rev. B37, (1988), 7850.

5. E. Batalla, E.G. Zwartz, R. Goudreault and L.S. Wright, Proc. Nato Adv. Study Institute, Bad Winsheim, Germany, July 1989.

6. M. Onoda, A. Yamamoto, E. Takayama-Muromachi and $\mathbf{S}$. Takekawa, Japanese Journal of Electronics, 27, (1988), L833. 